\title{
Primary vulvar leiomyosarcoma localized in the Bartholin's gland area: A case report and review
}

\author{
STELLA AKRIVI $^{1}$, MICHAIL VARRAS ${ }^{2}$, ZOI ANASTASIADI $^{3}$, CHRISTINA PAPPA $^{3}$, AIKATERINI VLACHIOTI $^{3}$, \\ VIKTORIA-KONSTANTINA VARRA ${ }^{4}$, FANI-NIKI VARRA ${ }^{5}$, EUFEMIA BALASI $^{6}$ and CHRISTOS AKRIVIS $^{3}$ \\ ${ }^{1}$ Department of Obstetrics and Gynecology, Royal Jubille Maternity Hospital, Belfast Trust, Belfast BT12 6BA, UK; \\ ${ }^{2}$ Fourth Department of Obstetrics and Gynecology, 'Elena Venizelou' General Hospital, Athens 11521; \\ ${ }^{3}$ Department of Obstetrics and Gynecology, 'G. Chatzikosta' General Hospital, Ioannina 45001, Epirus; \\ ${ }^{4}$ Department of Pharmacy, University of Patras, Patra 26504, Greece; ${ }^{5}$ Department of Pharmacy, Frederick University, \\ Nicosia 1036, Cyprus; ' ${ }^{6}$ Pathology Department, 'G. Chatzikosta' General Hospital, Ioannina 45001, Epirus, Greece
}

Received March 13, 2020; Accepted January 14, 2021

DOI: $10.3892 / \mathrm{mco} .2021 .2231$

\begin{abstract}
Vulvar sarcomas located in the Bartholin's gland area are extremely uncommon mesenchymal vulvar tumors. These neoplasms can be mistaken as Bartholin' gland benign lesions such as cysts or abscesses, leading to a delay in the diagnosis of underlying malignancy. Currently, only a few cases of these aggressive cancers have been reported in the literature. A 42-year-old female patient without any previous complaint presented to Obstetrics and Gynecology Department of 'G. Chaztikosta' General Hospital due to a vulvar lump in the area of the left Bartholin's gland with a 6-month history of progressive swelling. Pelvic examination showed a solid mass of $6.5-\mathrm{cm}$ in maximum diameter, localized in the left Bartholin's gland. The patient underwent wide local excision and histopathological examination of hematoxylin and eosin-stained sections indicated intersecting fascicles of spindle cells, with moderate to severe atypia. The number of mitoses was up to 8 per 10 high power fields. The neoplasm to its greatest extent was circumscribed and in places had an invasive growth pattern. Tumoral necrosis was not seen. Involved Bartholin' gland by the tumor was identified. The tumor extended focally to the surgical margin. The neoplastic cells showed positive staining for smooth muscle actin, desmin, HHF35, caldesmon, vimentin and estrogen and progesterone receptors. Immunohistochemistry was negative for S100, myoglobulin, keratin 116, CD117, CD34 and CD31. The patient denied further surgery or/and local radiotherapy, although the mass was $>5-\mathrm{cm}$ and a focally infiltrative surgical margin was found. During the close follow-up, no local recurrences or metastases
\end{abstract}

Correspondence to: Dr Michail Varras, Fourth Department of Obstetrics and Gynecology, 'Elena Venizelou' General Hospital, Plateia Elenas Venizelou 2, Ampelokipoi, Athens 11521, Greece E-mail: mnvarras@otenet.gr

Key words: Bartholin's gland, vulva, leiomyosarcoma, soft tissue, vulvar sarcoma, vulvar neoplasm, vulvar diseases were observed 53 months after surgery. In conclusion, wide local tumor excision with free surgical margins is a good option of surgery for vulvar leiomyosarcomas. In recurrences, a new extensive surgical resection of the lesion and radiotherapy are suggested. Ipsilateral lympadenectomy is indicated when there is a pathologic lymph node. Chemotherapy is provided in cases of distal metastases.

\section{Introduction}

Sarcomas are tumors with mesenchymal origin and very poor prognosis compromising of $2 \%$ of all cancer deaths. These neoplasms are very rare and account for 1 to $2 \%$ of all malignancies (1-7). Sarcomas of the female genital tract have a low frequency of $3 \%(4,8,9)$. In particular, vulvar sarcomas account for 1 to $2 \%$ of all the vulvar tumors, compared to the uterine sarcomas, which represent the vast majority of all sarcomas of the female reproductive system (90\%) (2,5-7).

Vulvar sarcomas comprise a highly heterogeneous group of histological types, which include leiomyosarcomas, epithelioid sarcomas, fibrosarcomas, liposarcomas, hemangiosarcomas, rhabdomyosarcomas, angiosarcomas, malignant hemagiopericytomas, neurogenous sarcomas, dermatofibrosarcomas protuberans, Ewing sarcomas, synovial sarcomas, clear cells carcinomas, malignant fibrous histiocytomas and sometimes aggressive angiomyxomas $(1,3,4,6,10-12)$. The age of the described patients with vulvar leiomyosarcomas at the time of clinical presentation ranged between 14 and 69 years of age, with an average age of approximately $30-40$ years $(4,6,13,14)$. Vulvar embryonal rhabdomyosarcoma typically presents in girls less than 8 years of age (15). The size of vulvar sarcomas varies between 2 and $10-\mathrm{cm}$ (4). Vulvar sarcomas are usually asymptomatic or they are characterized by non-specific clinical manifestations, such an enlarging vulvar mass with a local discomfort. Vulvar sarcomas located in the Bartholin's gland area are often misdiagnosed as their clinical manifestations are very similar to benign lesions. These lesions are most commonly misdiagnosed as Bartholin's cysts or abscesses resulting in delaying diagnosis and worsening 
the prognosis $(11,12,6)$. In these cases, the late symptoms include pain, ulceration, bleeding and voiding dysfunction $(3,6,11)$. Vulvar sarcomas are characterized by a high chance of metastasis; it seems that chemotherapy achieves regression of lung metastasis $(6,12,14,16)$.

Leiomyosarcomas are the most common histological variants of vulvar sarcomas (2,5,7,17-22). Vulvar leiomyosarcomas are considered to originate from the smooth muscles within erectile tissue, blood vessel walls, rough ligaments, dartos muscles, erector-pili muscles and from stem cells localized in Bartholin's gland (22-24). Leiomyosarcomas occur most frequently in the labia majora, followed in a decreasing order by the Bartholin's gland area, the pericloitoral area and the labia minora $(25,26)$. Localizations of leiomyosarcomas in the Bartholin's gland area are extremely rare and only few such cases are reported in the international literature $(1,2,5,7,10,12,13,17,18)$. The biological behavior of the vulvar leiomyosarcomas is not fully understood and very little information is available so far (1). Most of the described cases of vulvar leiomyosarcomas in the international literature are about patients from Western countries suggesting therefore genetic disposition and lifestyle connection (27). A possible carcinogenetic precursor of these neoplasms is the chronic inflammation. This hypothesis is supported by the findings of coexistence between vulvar leiomyosarcomas and longstanding lichen sclerosus (28). Also, another predisposing factor of vulvar leiomyosarcomas seems to be the pregnancy because occurrence of them during pregnancy has been reported $(10,17,29)$. It seems that the positivity of estrogen and progesterone receptors is implicated in the development of vulvar leiomyosarcomas. The potential impact of estrogens and progesterone signaling through their receptors may result in induction of proliferation and growth of DNA damaged cells resulting finally in tumorogenesis of the vulvar leiomyosarcomas $(10,17,29)$.

The histopathological examination of the excised mass confirms the diagnosis of the extremely rare entity of vulvar leiomyosarcomas $(2,5,7)$. Given the extreme rarity of vulvar leiomyosarcomas, an optimal treatment strategy has not yet been elucidated. It seems that their primary treatment of choice is the surgical excision, including wide local excision or radical hemivulvectomy. The usefulness of ipsilateral lymphadenectomy in the treatment of vulvar leiomyosarcomas is not clear because these neoplasms metastasize mostly by the bloodstream compared to lymphogenous metastasis. Locally recurrent tumors require adjuvant treatment in the form of radiotherapy. Adjuvant chemotherapy is placed in the treatment of distal metastases; however the exact role of adjuvant chemotherapy and/or radiotherapy remains uncertain for vulvar leiomyosarcomas, which display very aggressive behavior and rapid progression $(2,5,7)$.

Herein, we present a very rare case of vulvar leiomyosarcoma localized in the Bartholin's gland area in a 42-year-old female and describe its histopathological and immunohistochemical features. Also, the current literature is reviewed in terms of clinical signs and symptoms, diagnosis, biological behavior, prognosis and treatment. Vulvar sarcomas located in the Bartholin's gland are often mistakenly considered as benign lesions resulting in delayed diagnosis.

\section{Case report}

A 42-year-old patient presented to outpatient clinic because of a vulvar lump in the area of the left Bartholin's gland with a 6-month history of progressive swelling. In her gynecological history, the patient reported laparoscopic hysterectomy without salpingo-oophorectomy, two years ago, due to heavy metrorrhagia and the uterus was taken out through the vagina directly. The final histological exam of the hysterectomy showed benign leiomyomas within the uterus.

Pelvic examination showed a solid mass of $6.5-\mathrm{cm}$ in maximum diameter, in the area of the left Bartholin's gland. Palpation of the inguinal lymph nodes in either groin was normal; there were no palpable nodes. The patient underwent wide local excision and the mass was enucleated completely from the bed. The surgical specimen was sent for pathological examination. We did not indicate a biopsy of the mass before the excision because our initial clinical diagnosis was as a chronic left Bartholin's gland abscess.

Macroscopically, the tumor was $6.5 \times 4.5 \times 3.5-\mathrm{cm}$ in size with regular margins. Cut surface showed a whitish, homogeneous lesion with fibroelastic consistency.

Microscopic examination of the hematoxylin and eosin-stained sections showed intersecting fascicles of spindle cells (Fig. 1A and B), with moderate to severe atypia (Fig. 2A and B). The number of mitoses was up to 8 per 10 high power fields (Fig. 3A). The neoplasm to its greatest extent was circumscribed and in places had an invasive growth pattern. Tumoral necrosis was not seen. Involved Bartholin' gland by the tumor was identified. The tumor extended focally to the surgical margin (Fig. 3B). The neoplastic cells showed positive staining for smooth muscle actin (SMA) (Fig. 4A), desmin (Fig. 4B), HHF35 (Fig. 4C), caldesmon (Fig. 5A), vimentin (Fig. 5B) and estrogen (Fig. 5C) and progesterone receptors (Fig. 5D). Immunohistochemistry was negative for S100, myoglobulin, keratin 116, CD117, CD34 and CD31.

Thoracic and upper and lower abdominal CT scans were negative for malignancy. Also, pelvic MRI was non suggestive for infiltrative pelvic lymph nodes. The diagnosis was primary vulvar leiomyosarcoma, localized in the Bartholin's gland area. The patient was discharged from the hospital and during the follow-up, every four months, no local recurrences or metastases of the disease were observed 53 months after surgery and the patient is in excellent physical condition. Although the mass was greater than $5-\mathrm{cm}$ and a focally infiltrated surgical margin was found in the histological specimen, the patient denied further surgery or/and local radiotherapy. During the close follow-up the patient did not complain about itching, burning, pain, numbness at the treatment site, body image disturbance or sexual problems.

\section{Discussion}

Primary vulvar leiomyosarcomas are extremely rare tumors and the localization of these tumors in the Bartholin's gland area results in diagnostic delays (7). Clinical differential diagnosis of vulvar leiomyosarcomas located in the Bartholin's gland area include Bartholin's gland cyst or abscess, infectious granuloma, syringeal, lipoma, fibroma, leiomyoma, hidradenoma, hidradentis suppurativa, hematoma, endometriosis, 

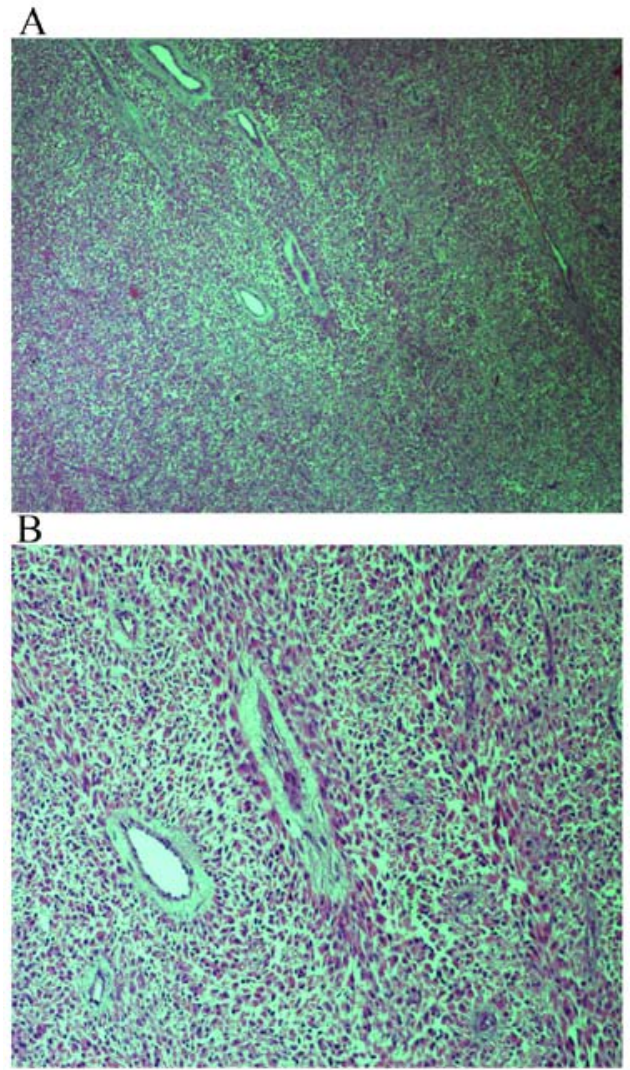

Figure 1. Spindle cell neoplasm with storiform pattern. Hematoxylin and eosin staining of tumor tissues at a magnification of (A) x40 and (B) x100.

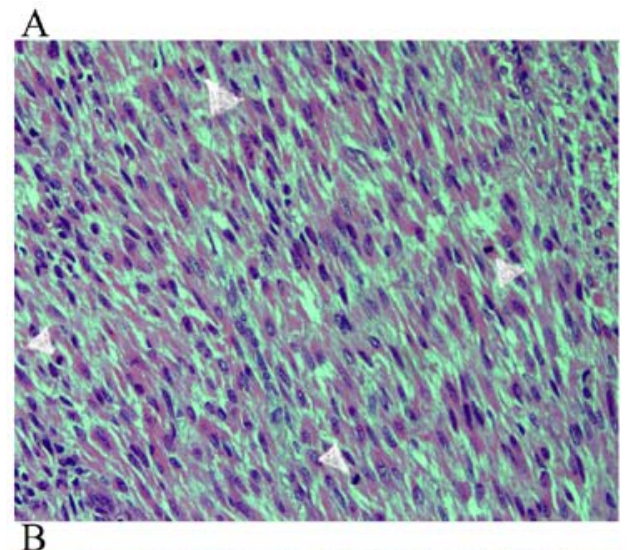

B

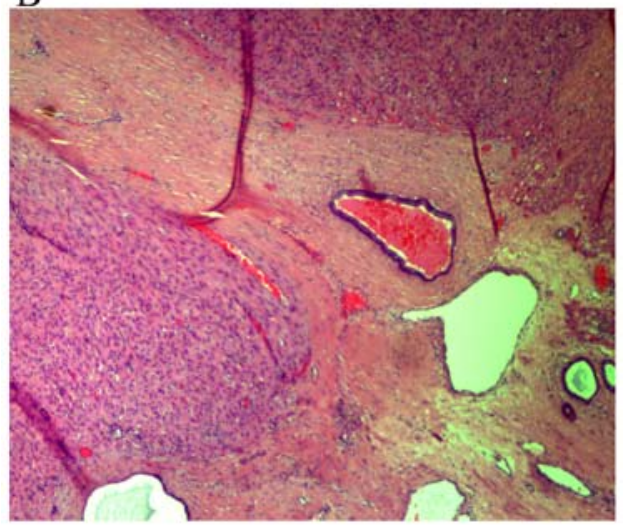

Figure 3. Presence of mitotic figures. (A) Hematoxylin and eosin staining of tumor tissues at a magnification of x200. (B) Focally infiltrated margin, hematoxylin and eosin staining of tissue at a magnification of $\mathrm{x} 40$.

accessory breast gland, warts, paraganglioma or squamous cell carcinoma, adenosquamous carcinoma, adenocarcinoma, adenoid cystic carcinoma, small cell carcinoma, transitional carcinoma, differential carcinoma, melanoma, spindle cell synovial sarcoma, embryonal rhabdomyosarcoma, dermatofibrosarcoma, malignant fibrous histiocytoma, extraskeletal Ewing's sarcoma, hibrosarcoma and epithelioid sarcoma (4,7,30-38). Furthermore, when the tumor is located in the Bartholin's gland, leiomyosarcoma should be distinguished from adenosarcoma, which is composed by a mixture of benign glandular epithelium and a malignant sarcomatous stroma $(39,40)$. Diagnosis is made by the histopathological examination of a biopsy of the lesion or of the complete excision of the neoplasm. In our case, non-epithelial component was identified microscopically in the tumor and therefore we concluded the diagnosis of vulvar leiomyosarcoma. Metastatic dissemination of vulvar leiomyosarcomas is thought to be through the hematogenous routes. The most common sites of distant metastatic sites have been reported to be the liver and the lungs and occasionally the bones $(1,37)$. The role of the lymphogenous routes for the metastatic dissemination of vulvar leiomyosarcomas is questionable (28).

Vulvar leiomyosarcomas can be distinguished from vulvar leiomyomas or vulvar atypical leiomyomas according to the suggestions of Nielsen et al (38). Three or more of the following histological and pathological characteristics are important for the diagnosis of vulvar leiomyosarcomas: i) The tumor has size greater than $5-\mathrm{cm}$ in diameter; ii) infiltration is seen in the margins of the
Figure 2. Moderate to severe cytological atypia. (A) Severe cytologica atypia; hematoxylin and eosin staining of tumor tissues at a magnification of x100. (B) Moderate cytological atypia; hematoxylin and eosin staining of tumor tissues at a magnification of $\times 100$. 


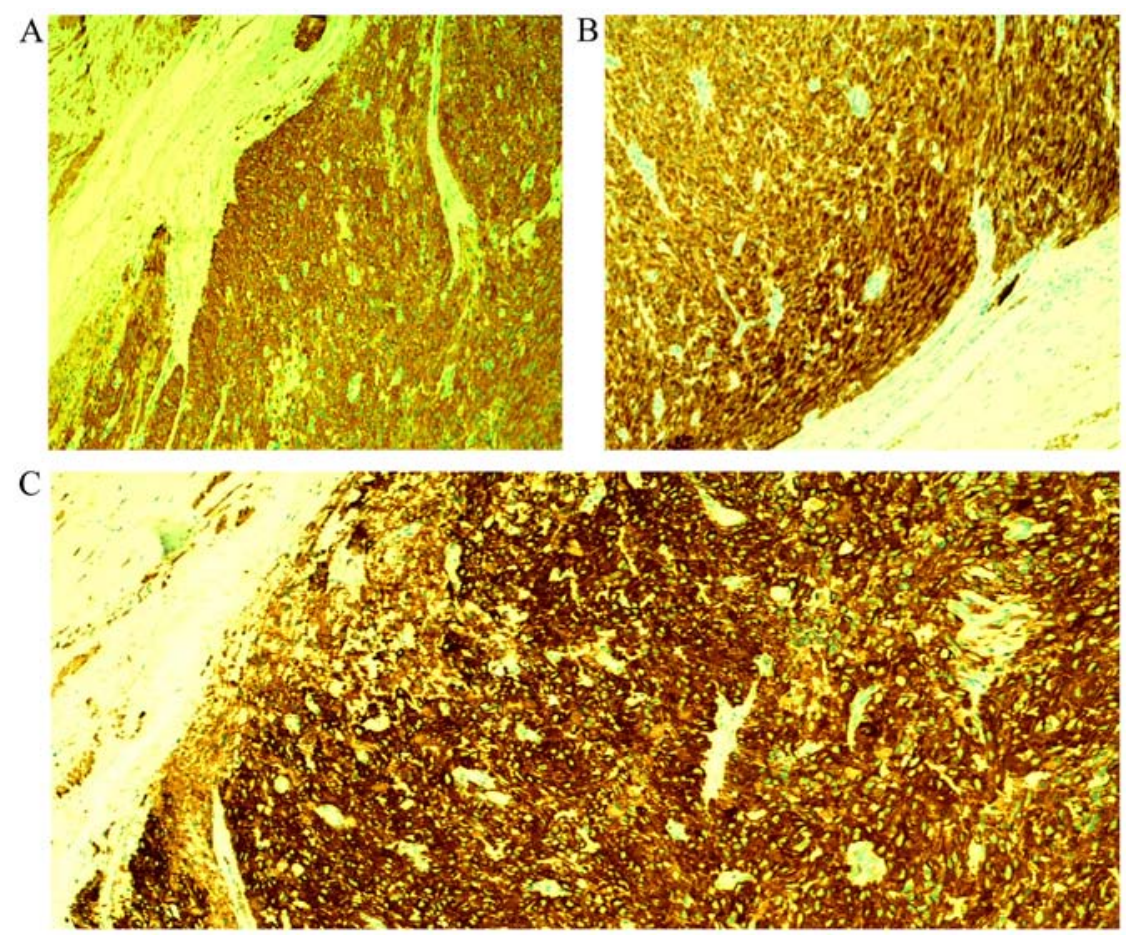

Figure 4. Immunohistochemical expression of spindled tumor cells for (A) SMA at a magnification of x100; (B) desmin at a magnification of x100; and (C) HHF35 at a magnification of $\times 40$.
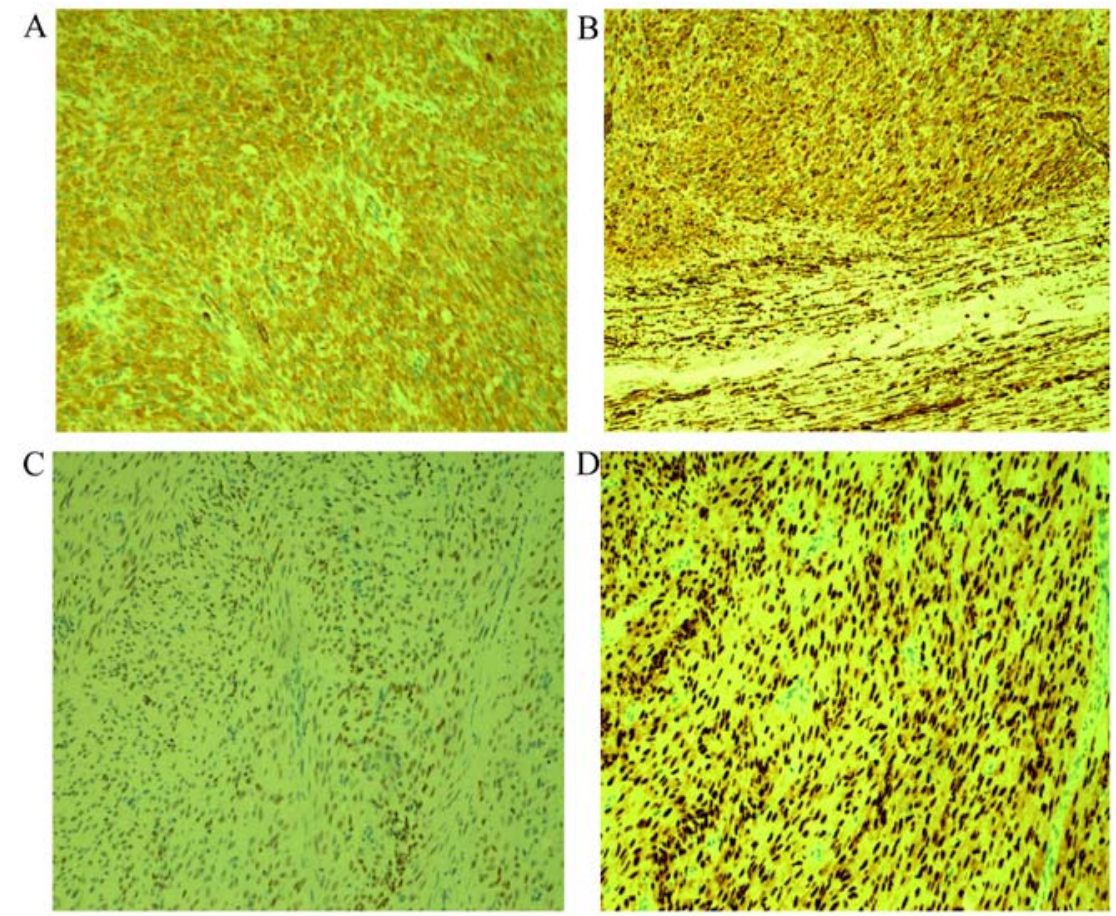

Figure 5. Immunoreactivity of spindled tumor cells for (A) caldesmon at a magnification of x100; (B) vimentin at a magnification of x10; (C) estrogen receptors at a magnification of x100; and (D) progesterone receptors at a magnification of x100.

tumor; iii) the tumoral background consists of more than five mitotic figures per 10 high-power fields; and iv) the tumoral cells show moderate to severe atypia. Leiomyomas exhibit only one of the above features; atypical leiomyomas exhibit only two of these features (38). Both leiomyomas and leiomyosarcomas exhibit immunopositivity for muscle markers including smooth muscle actin, muscle-specific actin and desmin and focal positivity for S-100 and cytokeratin (10). In our case, the neoplastic cells showed positive staining for smooth muscle actin (SMA), desmin, HHF35, caldsmon, vimentin and estrogen and progesterone receptors (Figs. 4 and 5).

A preoperative biopsy of vulvar masses located in the Bartholin's gland area and particularly in those with a compli- 


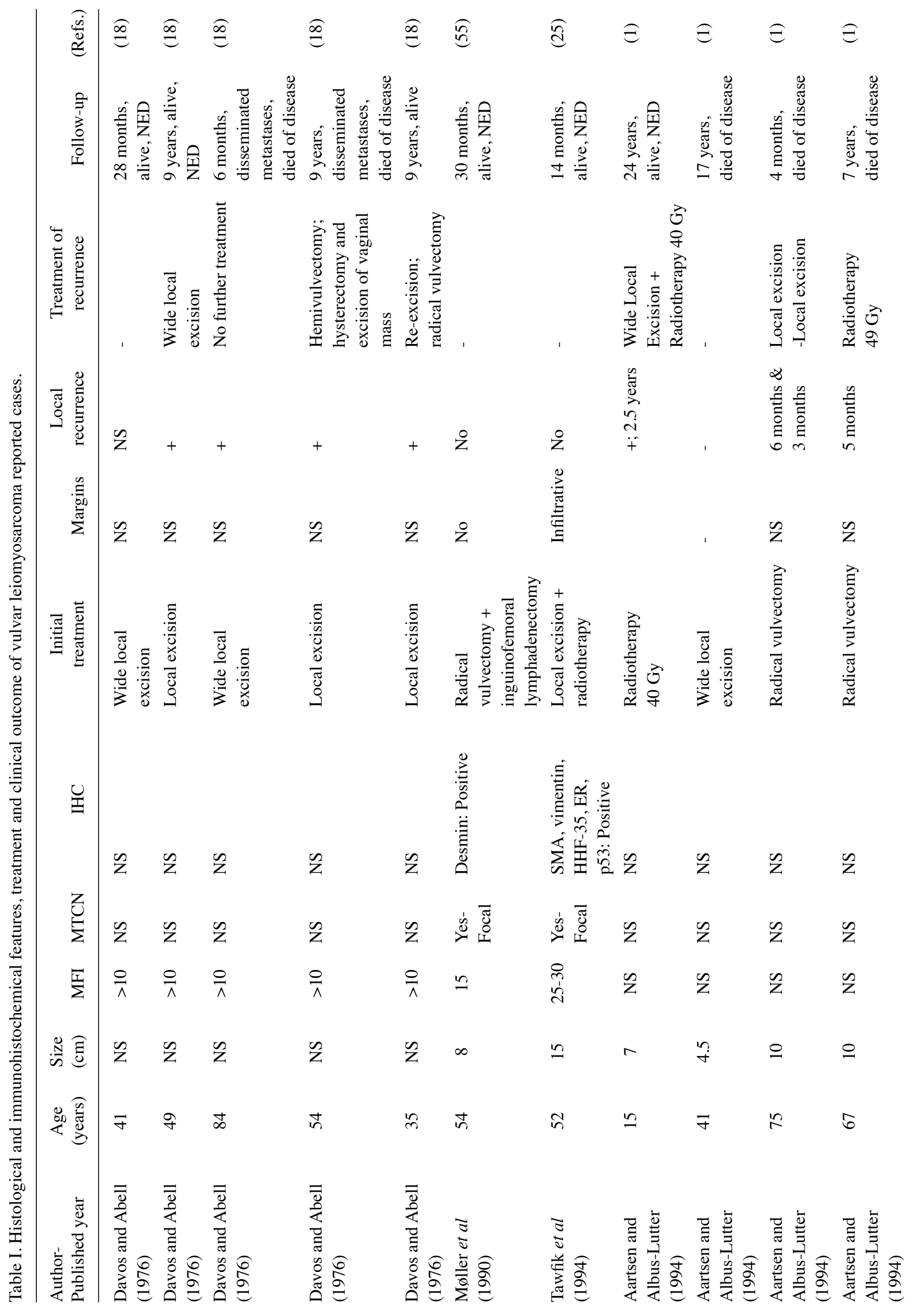




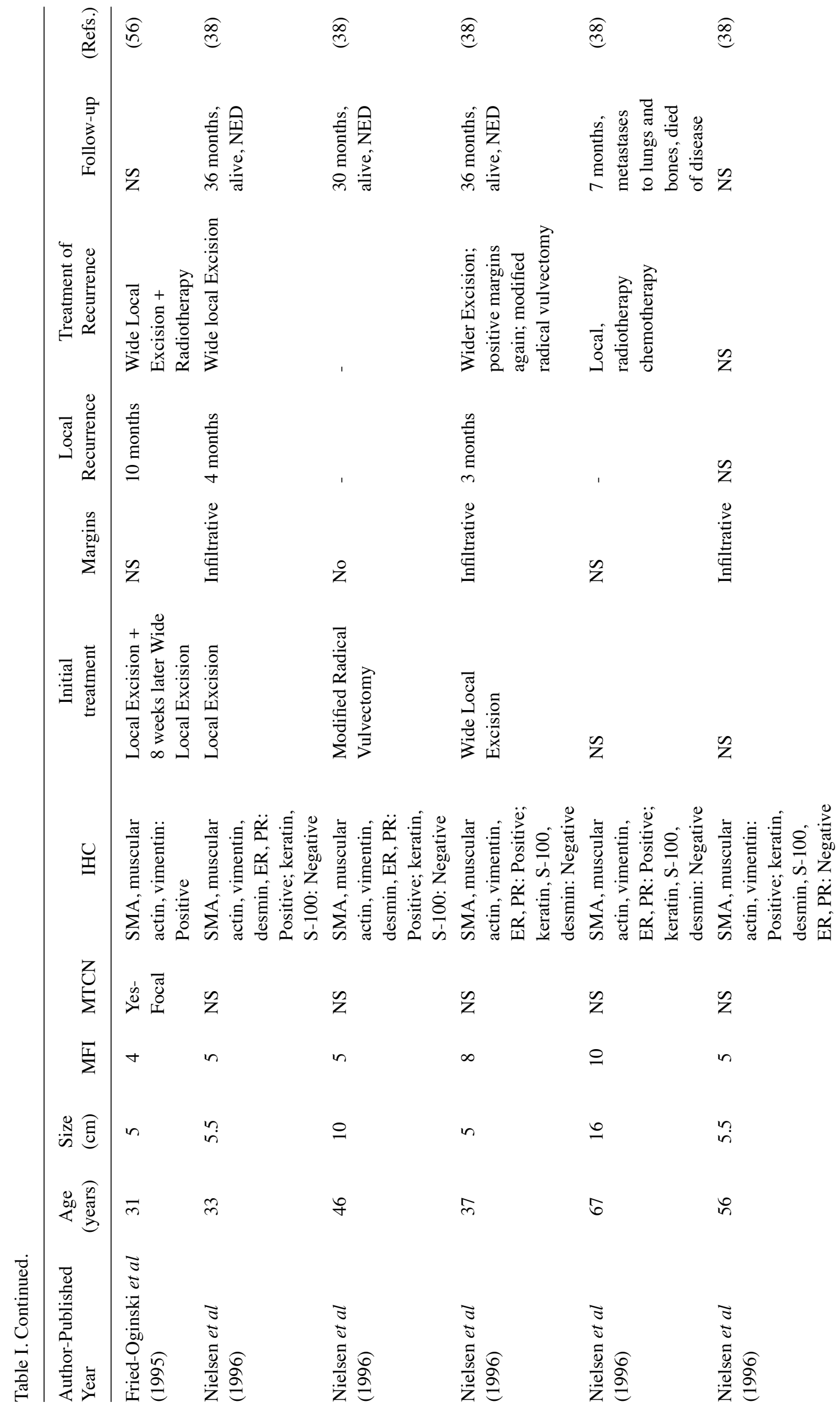




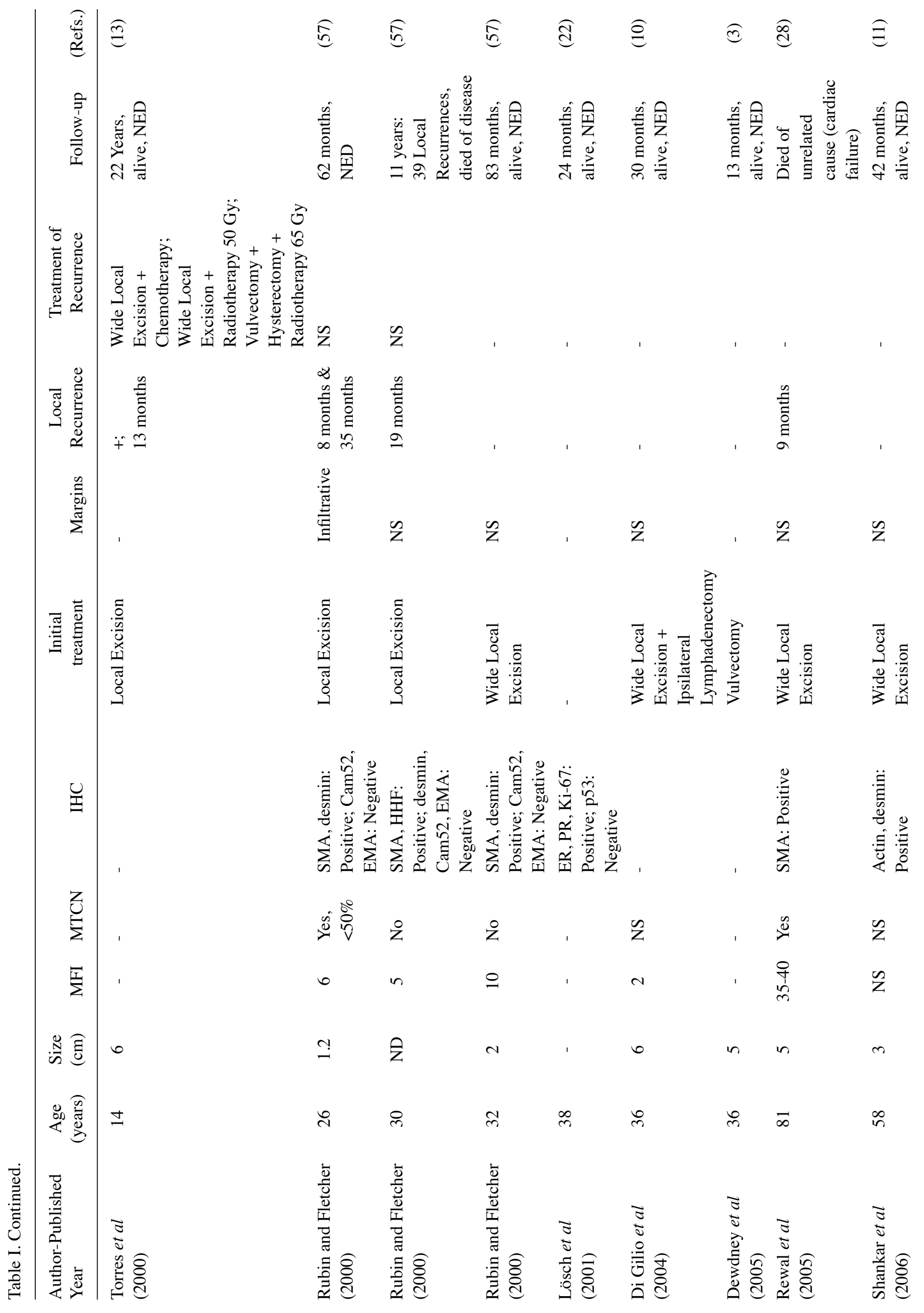




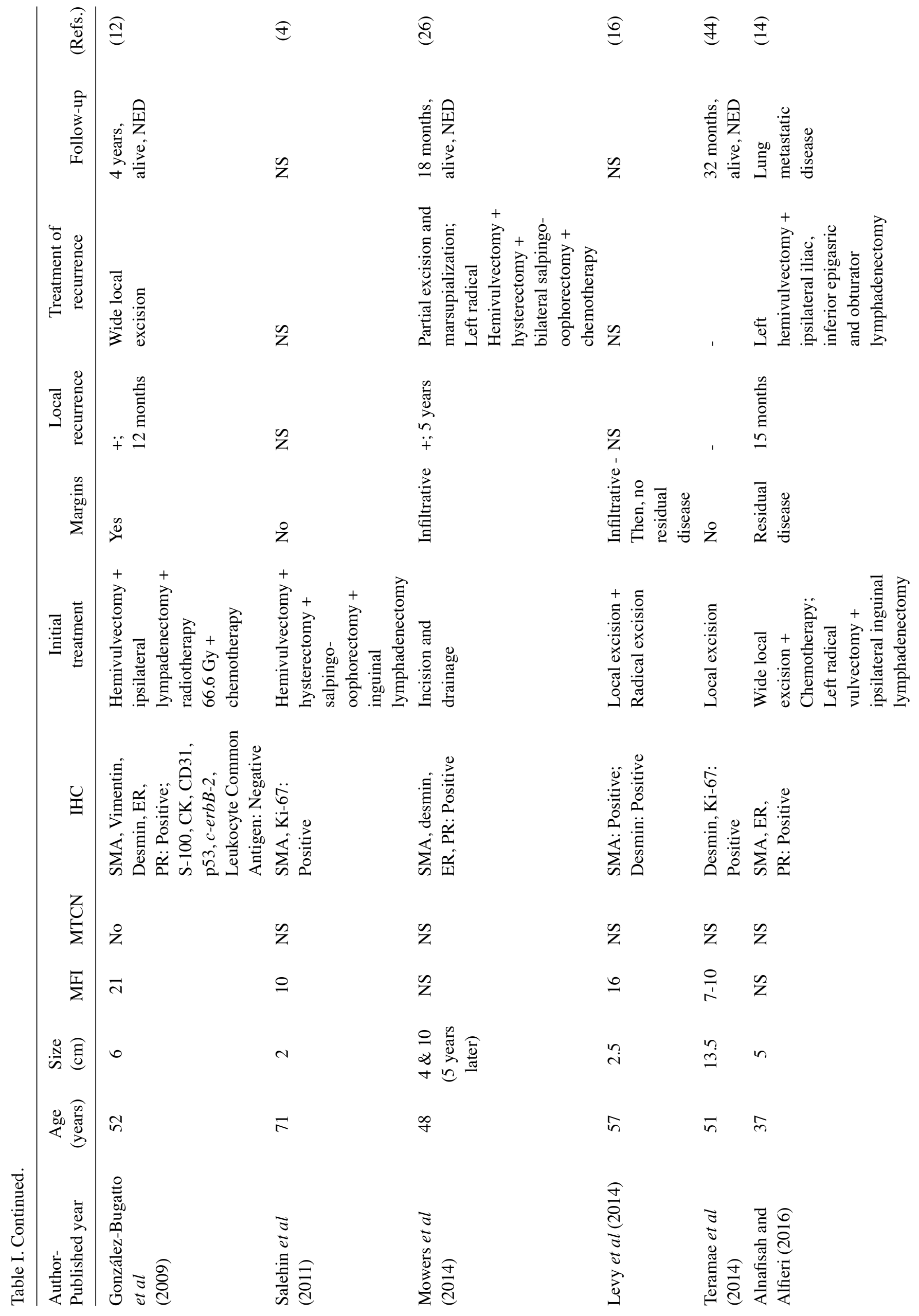




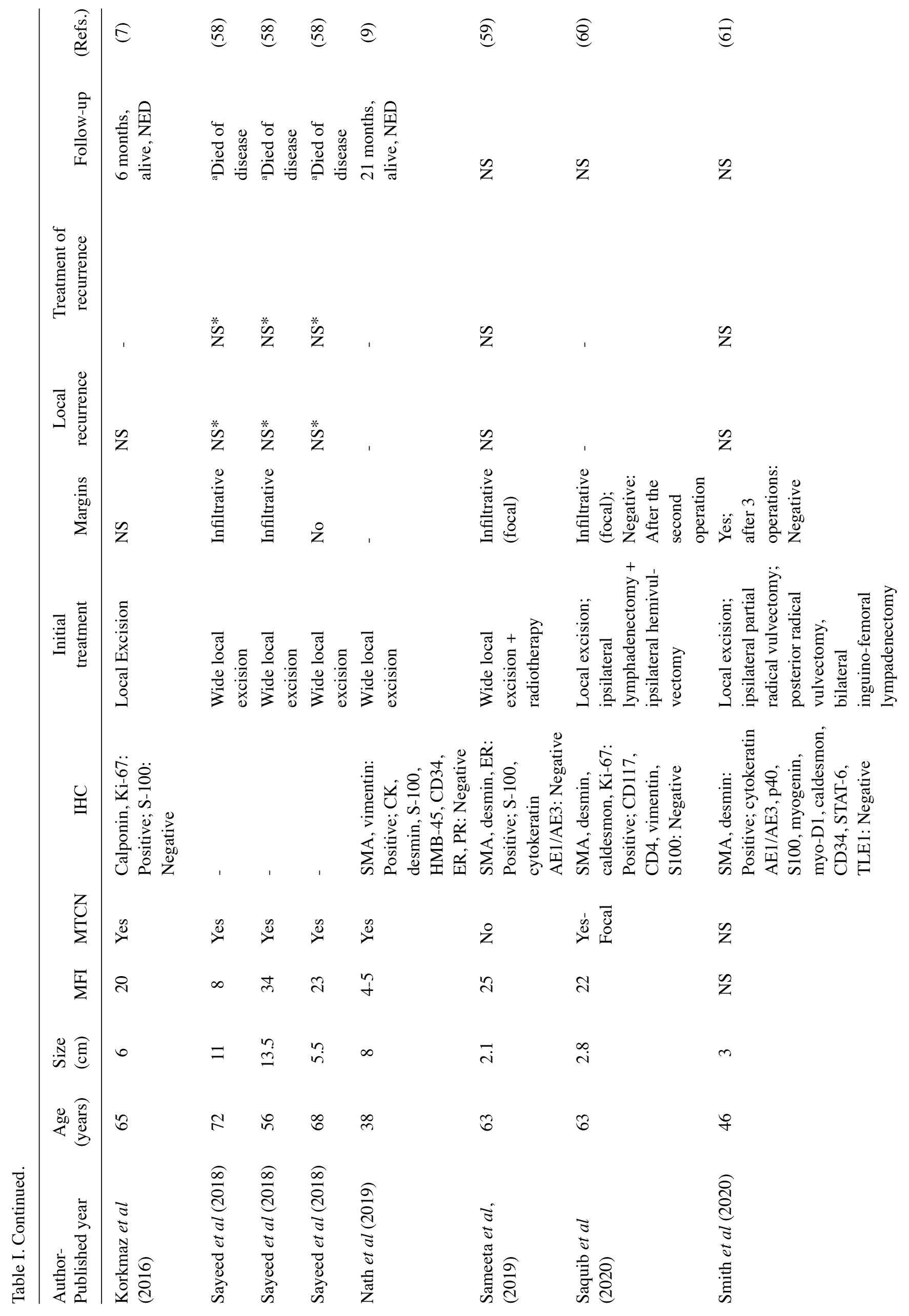




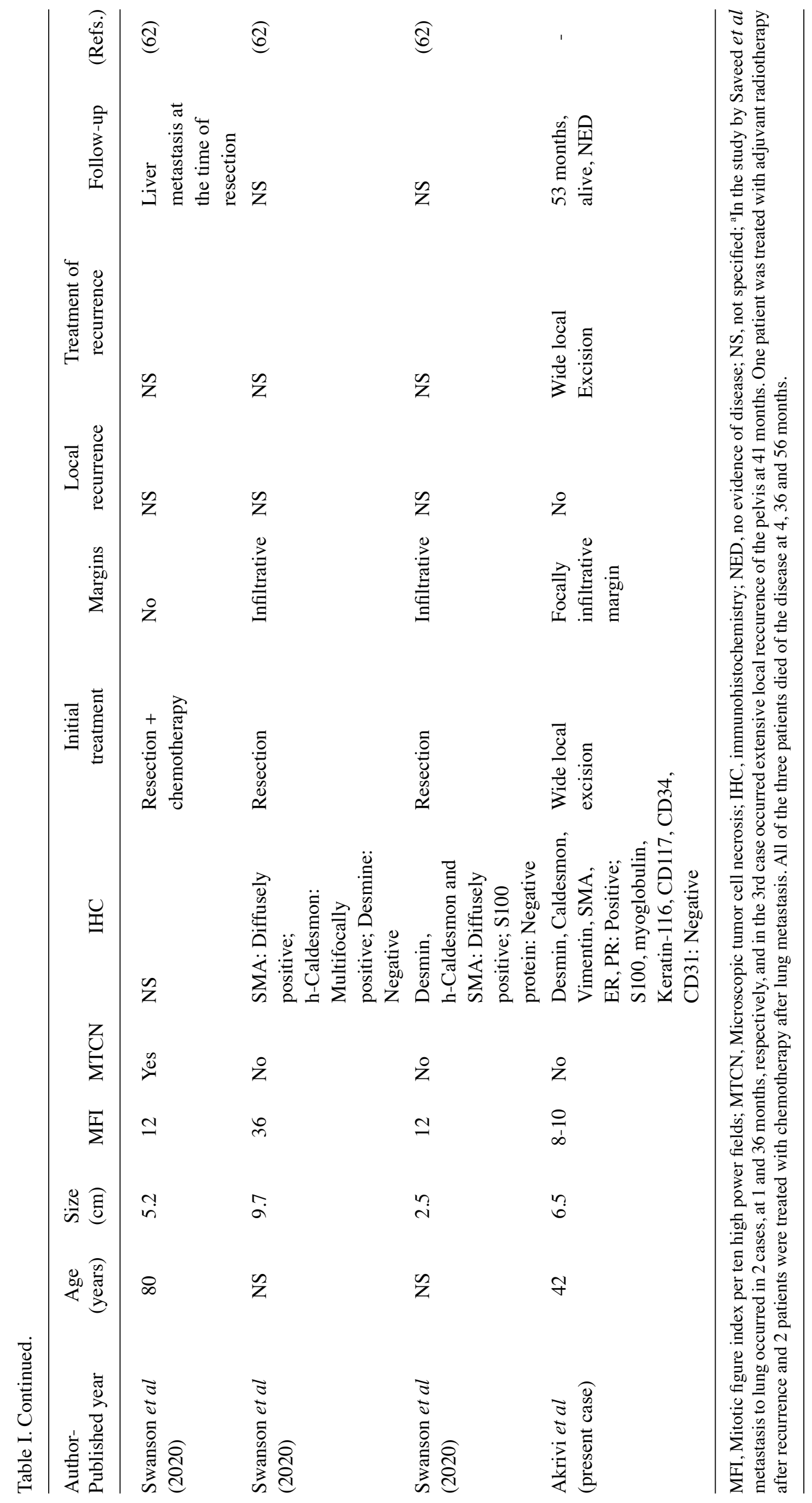


cated appearance is highly recommended because early diagnosis is important for curative treatment without delays of these extremely rare neoplasms $(3,7,12,16,26)$. However, in our case we did not indicate a biopsy of the mass before operation because our preoperative diagnosis was as a chronic Bartholin's gland abscess. Superficial lymphadenopathy is due to a cyst, inflammation, lymphoma or metastatic malignant tumor $(41,42)$. In the presence of a pathognomonic inguinal node the use of fine-needle aspiration biopsy is an easy, reliable and safe office procedure, which immediately provides an important tool of diagnosis (41). In the study by Altinboğa and Yüce (43) the lymph node fine-needle aspiration cytology (FNAC) showed sensitivity of $95.4 \%$, specificity of $94.1 \%$, positive predictive value of $95.4 \%$ and negative predictive value of $94.1 \%$ (43).

The first-line treatment involves surgical excision of the lesion. Localized disease is usually managed with wide local excision with surgically free margins. According to Aartsen and Albus-Lutter (1) the width of normal margin-tissue proposed for the surgeon doing the excision is 2-cm and for the pathologist $1-\mathrm{cm}$ because of the shrinking effect. Poor prognostic factors are considered to be mitotic rate more than 10 mitotic figures per $10 \mathrm{HPF}$, high histological grade, tumor size $>5-\mathrm{cm}$, local recurrence and distal metastases $(38,44)$. These neoplasms tend to metastasize by bloodstream and therefore ipsilateral lymphadenectomy is questionable (28). The decision to treat with vulvectomy is made by the size of the lesion $(7,10,18)$. Inguinal lymphadenectomy does not improve treatment $(1,22)$. The available data is limited and uncertain regarding radiosensitivity and chemosensitivity in the treatment of the vulvar leiomyosarcomas. However, in the presence of negative prognostic factors radiotherapy and chemotherapy should be given. Important favorite prognostic factors are the lower grade of nuclear atypia, the smaller tumoral size, the pathological confirmation of at least $2-\mathrm{cm}$ negative surgical margins and the absence of local recurrences $(1,2,12,14,22,38)$. Favor immunohistochemical factors include the overexpression of estrogen, progesterone and androgen receptors, the moderate immunopositivity for $\mathrm{Ki}-67$ and the absence of p53 expression $(4,22)$. It seems that the type of operation with inadequately resected tumors is the most significant negative prognostic factor for the appearance of local recurrences and distal metastases, compared to tumoral size of more than 5-cm (1). In addition to these factors, vulvar leiomyosarcomas with more aggressive behavior are defined on the basis of high cellularity, anaplasia, mitotic activity more than ten per 10 high-power fields, high grade of nuclear atypia and presence of tumoral necrosis $(12,16)$. The indications for radiotherapy includes: a) positive margin tumor involvement at the initial surgical treatment and b) tumor size $>5$-cm $(22,25,38,44,45)$. Pharmacogenomics biomarkers for the prediction of response to chemotherapeutic regimens seem to be involved in the improvement of molecular diagnostics in treatment of a specific subset of patients with soft tissue sarcomas. Actually, human equilibrative nucleotide transporter 1 (hENT1) is a molecular biomarker that could predict gemcitabine efficacy in leiomyosarcoma (46). Furthermore, TP53 mutations are significantly associated with longer progression-free survival compared to TP53 wild-type (47). In addition, after 12 weeks of treatment with pazopanib, it has been found that the progression-free survival was positively correlated to high levels of interleukin (IL)-12 and mitochondrial pyruvate carrier 3 (MPC3) levels and negatively correlated with low levels of VEGF2 and high levels of placental growth factor (PGF) (48). In addition, in soft tissue sarcoma the activity of trabectedin was found to inversely correlate with the mRNA levels of BRCA1. Particularly, low levels of mRNA BRCA1 expression were associated with improvement in outcome of patients (49).

In our case, the neoplastic cells showed positive staining for estrogen and progesterone receptors (Fig. 5C and D), suggesting the potential role of estrogen and progesterone in the development and progression of vulvar leiomyosarcoma. However, in our case we did not examine the pre- and post-operative serum estrogen levels of our patient. Nethertheless, the predisposing role of estrogen and progesterone in vulvar leiomyosarcoma tumorogenesis is supported by their occurrence during pregnancy $(10,17,29)$. It is possible that the positivity of estrogen and progesterone receptors may initiate the proliferation and growth of DNA damaged cells resulting in development and progression of vulvar leiomyosarcoma $(10,17,29)$. The role of aromatase inhibitors (AIs), selective estrogen receptor modulators (SERMs), progestins and GnRH-analogues for the treatment of vulvar leiomyosarcoma and especially for their recurrences is not clear due to the rarity of this entity and the lack of clinical trials to determine the clinical efficacy and usefulness of the above regiments for first- and second-line therapies. However, we have some evidence in the case of uterine leiomyosarcoma. Particularly, patients with uterine leiomyosarcoma and a high expression rate of ER and PR show good response to hormonal therapy (50). Yamaguchi et al suggested that Letrozole as well as progestins could be the first choice for patients with recurrent or residual low-grade endometrial stromal sarcoma (51). It seems that letrozole is the first-line hormone drug for postoperative adjuvant therapy in patients with stage I uterine leiomyosarcoma, while exemestane and anastrozole are for second-line treatment in patients with recurrent, metastatic and unresectable uterine leiomyosarcoma (52). In a clinical trial by George et al (53) of 27 postmenopausal women with metastatic and/or unresectable uterine leiomyosarcoma with positive estrogen receptors and/or postive progesteron receptors it has been found that the rate of stable disease was $54 \%$ in all patients and the 12 -week rate of progression free survival $50 \%$. These findings suggest that strong expression of estrogen and progesterone expression in tumors is related with longer progression free survival (53). On the other hand, the use of progestins in uterine leiomyosarcoma should be cautious because medroxyprogesterone acetate in higher doses (5 mg/day) is able to significantly increase the growth of this neoplasm (52). In addition, it has been found that patients who receive tamoxifen treatment for more than five years show an increase in the incidence of uterine leiomyosarcoma to $17 / 100,000$ women yearly $(50,54)$. Therefore, tamoxifen is contraindicated for the treatment of uterine leiomyosarcoma (52).

In the present case, we chose to treat our patient with wide local excision because of the patients' age. Also, after the histopathological confirmation of the disease, in view of the absence of pelvic lymph node infiltration suggested by the MRI examination, inguinal lymphadenectomy was decided 
not to be done. Our patient denied radiotherapy although the tumor extended focally to the surgical margin. In such cases, we recommend radiotherapy because the risk of local recurrence is related to the inadequate resection margins and not to the size of the tumor (39). Furthermore, Aartsen and Albus-Lutter suggested that the degree of differentiation should not be determined for the case of vulvar leiomyosarcoma (1). Therefore, in our case we did not indicate the grade of the vulvar leiomyosarcoma localized in the Bartholin's gland area. In addition, in the present study we resumed reported cases of vulvar leiomyosarcoma in a table according to their histological and immunohistochemical features, treatment and clinical outcome (Table I).

In conclusions, any vulvar lesion with unusual characteristics in the Bartholin's gland area should be carefully evaluated. Vulvar leiomyosarcomas localized in the Bartholin's gland area could masquerade as chronic Bartholin's gland abscess or as a benign lesion. For vulvar leiomyosarcomas, a wide local excision of the mass with free surgical margins should be a good option of surgery. This is particularly important to perform an effective surgery in cases with these extremely rare neoplasms to avoid recurrences and distal metastases. In case of recurrence, a new extensive surgical resection of the lesion with ipsilateral lympadenectomy and radiotherapy are suggested. Chemotherapy is given in cases of distal metastases.

\section{Acknowledgements}

Not applicable.

\section{Funding}

No funding was received.

\section{Availability of data and materials}

The datasets used and analyzed during the current study are available from the corresponding author on reasonable request.

\section{Authors' contributions}

$\mathrm{CA}, \mathrm{ZA}, \mathrm{CP}, \mathrm{AV}$ were involved treated the patient. SA, MV, $\mathrm{ZA}, \mathrm{CP}, \mathrm{AV}, \mathrm{EB}, \mathrm{CA}$, conceived and designed this case report. SA, MV, ZA, CP, AV, VKV, FNV, EB, CA, wrote the initial draft of the report. SA, ZA, CP, AV, EB, CA, collected the clinical data. EB performed histopathological and immunohistochemical analysis and provided the related images. CA, $\mathrm{ZA}$ and $\mathrm{EB}$ were responsible for confirming the assessment of the authenticity of all the raw data. All authors have read and approved the final version of the manuscript.

\section{Ethics approval and consent to participate}

Not applicable.

\section{Patient consent for publication}

The patient gave written informed consent for publication of the case details and associated images.

\section{Competing interests}

The authors declare that they have no competing interests.

\section{References}

1. Aartsen EJ and Albus-Lutter CE: Vulvar sarcoma: Clinical implications. Eur J Obstet Gynecol Reprod Biol 56: 181-189, 1994.

2. Curtin JP, Saigo P, Slucher B, Venkatraman ES, Mychalczak B and Hoskins WJ: Soft-tissue sarcoma of the vagina and vulva: A clinicopathologic study. Obstet Gynecol 86: 269-272, 1995.

3. Dewdney S, Kennedy CM and Galask RP: Leiomyosarcoma of the vulva: A case report. J Reprod Med 50: 630-632, 2005.

4. Salehin D, Haugk C, William M, Hemmerlein B, Thill M, Diedrich K and Friedrich M: Leiomyosarcoma of the vulva. Eur J Gynecol Oncol 33: 306-308, 2012.

5. Duganzija T, Mikov MM, Salajic N, Nikolin B, Trifunovic J and Ilic M: Increasing frequency of soft tissue sarcomas in Vojvodina-comparison with the literature. Asian Pac J Cancer Prev 15: 1011-1014, 2014

6. Chokoeva AA, Tchernev G, Cardoso JC, Tatterson JW, Dechev I, Valkanov S, Zanardelli M, Lotti T and Wollina U: Vulvar sarcomas: Short guideline for histopathological recognition and clinical management. Part I. Int J Immunopath Pharmacol 28: 168-177, 2015.

7. Korkmaz V, Kurdoğlu Z, Kardag B, Arslanca T, Caydere M and Ergun Y: A rare case of leiomyosarcoma localized in the Bartholin's gland area and review of the literature. J Obstet Gynaecol Res 42: 589-592, 2016.

8. Youssef A, Neji K, M'Barki M, Ben Amara F, Malek M and Reziga H: Leimyoma of the vulva. Tunis Med 91: 78-80, 2013.

9. Nath B, Gaikwad HS, Rajamani N, Chouhan M, Sharma M and Topden S: Vulvar smooth muscle tumours: Case series and review of the literature. J Clin Diagn Res 13: QR01-QR04, 2019.

10. Di Gilio AR, Cormio G, Resta L, Carriero C, Loizzi V, Parisi AM and Selvaggi L: Rapid growth of myxoid leiomyosarcoma of the vulva during pregnancy: A case report. Int J Gynecol Cancer 14: 172-175, 2004.

11. Shankar S, Todd PM, Rytina E and Crawford RA: Leiomyosarcoma of the vulva. J Eur Acad Derm Venereol 20: 116-117, 2006.

12. González-Bugatto F, Añón-Requena, López-Guerrero MA, Báez-Perea JM, Bartha JL and Hervías-Vivancos B: Vulvar leiomyosarcoma in Bartholin's gland area: A case report and literature review. Arch Gynecol Obstet 279: 171-174, 2009.

13. Torres Lobaton A, Cruz Ortiz H, Rojo Herrera G and Avila Medrano L: Sarcomas of the vulva. Report of 2 cases. Ginecol Obstet Mex 68: 429-434, 2000 (In Spanish).

14. Alnafisah F and Alfieri J: Lung Metastasis in a case of recurrent poorly differentiated leiomyosarcoma of the Bartholin Gland: A case report and review of the literature. Cureus 8: e550, 2016.

15. Youngstrom EA and Bartkowski DP: Vulvar embyonal rhabdomyosarcoma: A case report. J Pediatr Urol 9:e144-e146, 2013.

16. Levy RA, Winham WM, Bryant CS and Quick CM: Smooth muscle neoplasms of the vulva masquerading as Bartholin gland duct cysts. Proc (Bayl Univ Med Cent) 27: 25-27, 2014.

17. Kuller JA, Zucker PK and Peng TC: Vulvar leiomyosarcoma in pregnancy. Am J Obstet Gynecol 162: 164-166, 1990.

18. Davos I and Abell MR: Soft tissue sarcomas of vulva. Gynecol Oncol 4: 70-86, 1976.

19. Tavassoli PA and Norris HJ: Smooth muscle tumors of the vulva. Obstet Gynecol 53: 213-217, 1979.

20. Newman PL and Fletcher CD: Smooth muscle tumors of the extreme genitalia: Clinicopathological analysis of a series. Histopathology 18: 523-529, 1991.

21. Grove A and Backman Nøhr S: Supperficial perineal leiomyosarcoma in an adolescent female and review of the literature including vulvar leiomyosarcomas. APMIS 100: 1081-1088,

22. Lösch A, Joura EA, Stani J, Breitenecker G and Lahodny J: Leiomyosarcoma of the vulva. A case report. J Reprod Med 46: 609-612, 2001.

23. Kaufman RH and Gardner HL: Benigh mesodermal tumors. Clin Obstet Gynec 8: 953-981, 1965.

24. Reyad MM, Gazvani MR and Khine MM: A rare case of primary leiomyoma of the vulva. J Obstet Gynecol 26: 73-74, 2006. 
25. Tawfik O, Huntrakoon M, Collins J, Owiety T, Seoud MA and Weed J Jr: Leiomyosarcoma of the vulva: Report of a case. Gynaecol Oncol 54: 242-249, 1994.

26. Mowers EL, Shank JJ, Frisch N and Reynolds RK: Myxoid leiomyosarcoma of the Bartholin Gland. Obstet Gynecol 124 (Suppl 1): S433-S435, 2014.

27. Mensch LS, Trask CE and Eltabbakh GH: Leiomyosarcoma of the vulva: A brief communication. Eur J Gynaecol Oncol 21: 61, 2000.

28. Rawal N, Saridogan E, Khan N and Weekes A: Leiomyosarcoma of the vulva in association with lichen sclerosus. J Obstet Gynaecol 25: 87-88, 2005.

29. Bakri YN, Akhtar M, El-Senoussi M and Wierzbicki R: Vulvar sarcoma: A report of four cases. Gynecol Oncol 46: 384-390, 1992.

30. Tjalma WAA, Hauben EL, Deprez SME, Van Marck EA and van Dam PA: Epitheliod sarcomaof the vulva. Gynecol Oncol 73: 160-164, 1999

31. Khoury-Collado F, Elliott KS, Lee YC, Chen PC and Abulafia O Merkel cell carcinoma of the Bartholin's gland. Gynecol Oncol 97: 928-931, 2005

32. Woida FM and Ribeiro-Silva A: Adenoid cystic carcinoma of the Bartholin gland: An overview. Arch Pathol Lab Med 131: 796-798, 2007.

33. Kacerovska D, Nemcova J, Petrik R, Michal M and Kazakov DV: Lymphoepithelioma-like carcinoma of the Bartholin gland. Am J Dermatopathol 30: 586-589, 2008.

34. Kyriazi MA, Carvounis EE, Kitsou M, Arkadopoulos N, Nicolaidou E, Fotiou S and Smyrniotis V: Myoepithelial carcinoma of the vulva mimicking Bartholin gland abscess in a pregnant woman: Case report and review of literature. Inter J Gynecol Pathol 29: 501-504, 2010.

35. Lee MY, Dalpiaz A, Schwamb R, Miao Y, Waltzer W and Khan A: Clinical pathology of Bartholin's glands: A review of the literature. Curr Urol 8: 22-25, 2014.

36. Morandeira $\mathrm{C}$, Isusi $\mathrm{M}$, Bárcena MV, Lecumberri $\mathrm{G}$ and Ibañez A: Vulvar Leiomyosarcoma in Bartholin's Gland. Eurorad Case: 14583, 2017

37. Vural B, Ozkan S, Yildiz K, Corakçi A and Gürbüz Y: Malignant fibrous histiocytoma of the vulva: A case report. Arch Gynecol Obstet 273: 122-125, 2005

38. Nielsen GP, Rosenberg AE, Koerner FC, Young RH and Scully RE: Smooth-muscle tumors of the vulva. A clinicopathological study of 25 cases and review of the literature. Am J Surg Pathol 20: 779-793, 1996

39. Ramos P, Ruiz A, Carabias E, Piñero I, Garzon A and Alvarez I: Müllerian adenosarcoma of the cervix with heterogenous elements: Report of a case and review of the literature. Gynecol Oncol 84: 161-166, 2002

40. Gollard R, Kosty M, Bordin G, Wax A and Lancey C: Two unusual presentations of Müllerian adenosarcoma: Case reports, literature review and treatment considerations. Gynecol Oncol 59: 412-422, 1995.

41. Kline TS, Kannan V and Kline IK: Lymphadenopathy and aspiration biopsy cytology. Review of 376 superficial nodes. Cancer 54: 1076-1081, 1984

42. Choi AH, Bolaris M, Nguyen DK, Panosyan EH, Lasky JL III and Duane GB: Clinicocytopathological correlation in an atypical presentation of lymphadenopathy with review of literature. Am J Clin Pathol 143: 749-754, 2015

43. Altinboğa AA and Yüce G: Fine-needle aspiration cytology in the diagnosis of lymph nodes: Correlation with histopathological diagnosis. South Clin Ist Euras 30: 52-59, 2019.

44. Teramae M, Fukuda T, Iami K, Yamauchi M, Hashiguchi Y, Ichimura $\mathrm{T}$, Yasui $\mathrm{T}$ and Sumi T: Leiomyosarcoma of the vulva: A case report. Int J Reprod Contracept Obstet Gynecol 3: 225-228, 2014.

45. Guidozzi F, Sadan O, Koller AB and Marks SR: Combined chemotherapy and irradiation therapy after radical surgery for leiomyosarcoma of the vulva. A case report. S Afr Med J 71: 327-328, 1987
46. Vincenzi B, Stacchiotti S, Collini P, Pantano F, Rabitti C, Perrone G, Iuliani M, Baldi A, Badalamenti G, Sanfilippo R, et al: Human equilibrative nucleoside transporter 1 gene expression is associated with gemcitabine efficacy in advanced leiomyosarcoma and angiosarcoma. Br J Cancer 117: 340-346, 2017.

47. Koehler K, Liebner D and Chen JL: TP53 mutational status is predictive of pazopanib response in advanced sarcomas. Ann Oncol 27: 539-543, 2016.

48. Sleijfer S, Gorlia T, Lamers C, Burger H, Blay JY, Le Cesne A, Scurr M, Collin F, Pandite L, Marreaud S and Hohenberger P: Cytokine and angiogenic factors associated with efficacy and toxicity of pazopanib in advanced soft-tissue sarcoma: An EORTC-STBSG study. Br J Cancer 107: 639-645, 2012.

49. Schöffski P, Taron M, Jimeno J, Grosso F, Sanfilipio R, Casali PG, Le Cesne A, Jones RL, Blay JY, Poveda A, et al: Predictive impact of DNA repair functionality on clinical outcome of advanced sarcoma patients treated with trabectedin: A retrospective multicentric study. Eur J Cancer 47: 1006-1012, 2011.

50. Thanopoulou E, Thway K, Khabra K and Judson I: Treatment of hormone positive uterine leiomyosarcoma with aromatase inhibitors. Clin Sarcoma Res 4: 5, 2014.

51. Yamaguchi M, Erdenebaatar C, Saito F, Motohara T, Miyahara Y, Tashiro $\mathrm{H}$ and Katabuchi H: Long-term outcome of aromatase inhibitor therapy with letrozole in patients with advanced low-grade endometrial stromal sarcoma. Int J Gynecol Cancer 25: 1645-1651, 2015.

52. Zang Y, Dong M, Zhang K, Gao C, Guo F, Wang Y and Xue F: Hormonal therapy in uterine sarcomas. Cancer Med 8: 1339-1349, 2019.

53. George S, Feng Y, Manola J, Nucci MR, Butrynski JE, Morgan JA, Ramaiya N, Quek R, Penson RT, Wagner AJ, et al: Phase 2 trial of aromatase inhibition with letrozole in patients with uterine leiomyosarcomas expressing estrogen and/or progesterone receptors. Cancer 120: 738-743, 2014.

54. Ricci S, Stone RL and Fader AN: Uterine leiomyosarcoma: Epidemiology, contemporary treatment strategies and the impact of uterine morcellation. Gynecol Oncol 145: 208-216, 2017.

55. Møller KL, Nygaard Nielsen $M$ and Trolle C: Leiomyosarcoma vulvae. Acta Obstet Gynecol Scand 69: 187-189, 1990.

56. Fried-Oginski W, Lovecchio JL, Farahani G and Smilari T: Malignant myxoid sarcoma of the Bartholin gland in pregnancy. Am J Obstet Gynecol 173: 1633-1635, 1995.

57. Rubin BP and Fletcher CD: Myxoid leiomyosarcoma of soft tissue, an underrecognized variant. Am J Surg Pathol 24: 927-936, 2000.

58. Sayeed S, Xing D, Jenins SM, Weisman PS, Beuhler D, Warmke L, Uram-Tuculescu C, Bakkum-Gamez JN, Howitt BE, Cortese $\mathrm{C}$, et al: Criteria for risk stratification of vulvar and vaginal smooth muscle tumors: An evaluation of 71 cases comparing proposed classification systems. Am J Surg Pathol 42: 84-94, 2018.

59. Sameeta F, Haque M, Akbar S, Zotto VD and Kahn A: Leiomyosarcoma: A rare tumor of the vulva. Am J Clin Pathol 152 (Suppl 1): S37-S75, 2019.

60. Saquib S, Cherawala M, Abdel Rahman O and Keloth TE: Leiomyosarcoma of the vulva mimicking as chronic Bartholin cyst: A case report. Oman Med J 35: e153, 2020.

61. Smith S, Bou Zgheib N, Vallejos A and Cuda JD: Case report of leiomyosarcoma of the vulva: A rare pathology. Marshall J Med 6: 6, 2020

62. Swanson AA, Howitt BE and Schoolmeester JK: Criteria for risk stratification of vulvar and vaginal smooth muscle tumors: A follow-up study with application to leiomyoma variants, smooth muscle tumors of uncertain malignant potential, and leiomyosarcomas. Hum Pathol 103: 83-94, 2020.

This work is licensed under a Creative Commons Attribution-NonCommercial-NoDerivatives 4.0 International (CC BY-NC-ND 4.0) License. 